\title{
Simulacro en las tensiones y disputas de lo femenino y masculino en Montaña adentro de Marta Brunet
}

\author{
Simulacrum in the tensions and disputes of the feminine and masculine in Montaña \\ adentro by Marta Brunet
}

\author{
Francisco García Mendoza ${ }^{1}$
}

\begin{abstract}
Resumen
Este artículo revisa las estrategias utilizadas por Marta Brunet en su novela Montaña adentro (1923) para lograr validarse dentro del canon literario de su época. Tensionar lo femenino y lo masculino, así como asumir una máscara en su escritura, le permiten sostener su proyecto y lograr una posición relevante en el campo cultural dominado por concepciones y presupuestos masculinos. Se propone la obra Montaña adentro como lugar en donde puede leerse el simulacro y la permanente tensión de los signos que, finalmente, configuran su proyecto de escritura.
\end{abstract}

Palabras clave: Marta Brunet, canon literario, femenino/masculine, simulacro.

\begin{abstract}
This article reviews the strategies that Marta Brunet employs in her novel Montaña adentro (1923) to situate her work's validity within the confines of the literary canon at that time. To support her project, she creates tensions between the feminine and masculine and uses a variety of masks in her writing. This lets her achieve a significant position in the cultural field dominated by male conceptions and assumptions. Montaña adentro is proposed as a site for the reader's interpretation of a simulacrum within the permanent contention between the feminine and the masculine that ultimately shape her writing project.
\end{abstract}

Key words: Marta Brunet, literary canon, feminine/masculine, simulacrum

\section{Introducción}

El Premio Nacional de Literatura, máximo galardón de las letras del país, es quizá el punto culmine de validación tanto para la figura del escritor como para la totalidad de su obra. En la historia del premio solo cinco mujeres han sido reconocidas: Gabriela Mistral (1951), Marta Brunet (1961), Marcela Paz (1982), Isabel Allende (2010) y Diamela Eltit (2018). Ausencias

\footnotetext{
${ }^{1}$ Magíster en Literatura Latinoamericana y Chilena por la Universidad de Santiago de Chile. Estudiante de Doctorado en Literatura de la Pontificia Universidad Católica de Chile. Correo electrónico:frgarcia2 @uc.cl
} 
notables como María Luisa Bombal, contemporánea a Brunet, solo se explican por condicionantes externas a la obra literaria en sí, ligadas más bien a las tensiones y disputas del denominado campo cultural (Bourdieu, 1990).

La lista de 49 hombres y 5 mujeres revela una cuestión esencial: el canon literario es innegablemente masculino. No es de extrañar que, para poder ingresar a este espacio, en donde lo masculino se vincula a lo universal, algunas escritoras hayan adoptado ciertas estrategias escriturales para lograr el reconocimiento cultural de sus pares. A raíz de lo anterior y desde la ficción, surge la interrogante de las consecuencias que conlleva tanto asimilarse a la oficialidad como rebelarse contra la misma.

La investigadora Lorena Amaro plantea su propia lectura del ingreso de Brunet al canon literario nacional: "Habría que decir, pues, que Brunet fue admitida en 'el equipo', pero su inscripción entre los muchachos del canon se debe en gran medida a que ellos no supieron leerla o, peor aún, no quisieron hacerlo realmente (...)" (Amaro, 2014, p. 23). Si bien lo anterior enfatiza en la torpeza de la recepción -0 en la ceguera deliberada-, no desconoce la intencionalidad rebelde y desestabilizadora de su escritura, que pasó solapada ante los ojos de la crítica de la época. Amaro (2014) afirma que a Brunet no supieron leerla y por lo mismo fue capaz de sortear la marginación hegemónica masculina. La académica y crítica literaria Rubí Carreño, también tiene sus reparos al afirmar que “(...) el premio no es más que un gesto de caballerosidad (galantería) a una escritura capaz de ser como la de un hombre (recia)" (Carreño, 2002, p.47). En ese sentido y desde Bourdieu, se hace necesario leer y "(...) comprender la obra de arte como una manifestación del campo en su conjunto, en que se hallan depositadas todas las potencias del campo, y también todos los determinismos inherentes a la estructura y a funcionamiento de este (Bourdieu, 1990, p. 11).

El lugar que ocupa la escritura de Brunet en ese campo es una arista más bien artificiosa, considerando que todo premio de esta índole es también un gesto político que tiene que ver con las relaciones y posiciones en el sistema simbólico del campo cultural. Sin embargo, no deja de ser relevante el hecho de que Brunet y el resto de las escritoras galardonadas ocupen una posición subordinada dentro del espacio significante del premio y, más aún, atendiendo a las palabras de Carreño, su obra haya sido posicionada en un lugar en donde las lecturas e interpretaciones quedan acotadas a cierto tipo de imaginario rural y masculino. Lo anterior está directamente relacionado y encuentra su explicación en el cómo lo femenino ha sido desplegado e instaurado desde un discurso más bien patriarcal.

En este artículo se aborda la novela Montaña adentro (1923), su ópera prima, para identificar cómo las tensiones entre lo femenino y lo masculino funcionan como estrategia para asimilarse al modo de escribir oficial, para lograr acceder, finalmente, al canon nacional. Pensar al género como una máscara ambigua que estratégicamente muestra, a la vez que oculta, es el eje de este texto y cómo, a partir del gesto, los personajes transitan entre los signos inscritos de ese mismo género. Si bien algunos autores han insistido con la mascarada del criollismo adoptada por Brunet, en este análisis se ha optado por no abordarlo como tal, para privilegiar otros espacios de interpretación. No me interesa abordar la novela desde la perspectiva situacional en donde ruralidad y la "cuestión social" determinan, casi, su lectura. Lo anterior tiene que ver con no querer circunscribir mi análisis a una lectura más bien condicionada y, por consiguiente, evitar conclusiones totalizantes con respecto al amplio espectro de las novelas que comparten los elementos del criollismo. Propongo las representaciones de lo femenino y lo masculino más allá de sus correspondencias biológicas, más bien como un complejo entramado de subjetividades 
atravesadas por el poder en un sistema en donde históricamente lo femenino ha estado supeditado a lo masculino (espejeando su lugar en el canon) y que, sin embargo, en los textos trabajados configuran una dialéctica sígnica en constante disputa territorial ${ }^{2}$. La escritura de Brunet, por lo tanto, entra en ese modo de concebir la literatura y desde ahí se posiciona, por lo que se puede observar en su textualidad ciertas fisuras desde donde asoman las construcciones de lo femenino y masculino ${ }^{3}$.

En una primera instancia, se abordan las lecturas y propuestas de la obra de Brunet trabajadas por Eugenia Brito, Bernardita Llanos, Rubí Carreño, Martha E. Allen y Kemy Oyarzún, para establecer un marco teórico desde donde sostener el análisis literario. El segundo apartado propone un análisis crítico de la narración seleccionada en donde se establecen las huellas de lo femenino y lo masculino como articuladoras de la estrategia legitimizadora en la escritura de Marta Brunet. Aquí se trabaja específicamente el lenguaje utilizado en la construcción de la novela, los personajes, la maternidad y el matrimonio como instituciones obligatorias.

\section{Tres caminos para adentrarse en la montaña}

La poeta y crítica literaria Eugenia Brito, trabaja en su libro Ficciones del muro con dos textos de Marta Brunet: Piedra callada (1943) y Humo hacia el sur (1963). En sus dos ensayos aborda las relaciones femenino/masculinas desde “(...) la noción medular de subalternidad, planteada por Gramsci y posteriormente por Spivak, para reconocer el mecanismo relacional de fuerzas que conforman subjetividades carentes de interpelación (...)" (Zamorano, 2014, p. 177). De esta manera, Brito piensa el género como una máscara desde donde los personajes brunetianos intentan "revertir los signos de la opresión" (Brito, 2014, p. 22). Esta resistencia al orden político se da desde las tensiones y grietas que se producen entre lo masculino/dominante y lo femenino/sometido, articulado con una determinada realidad epocal:

El subordinado en Chile en la época de la que habla Brunet, es el peón de la hacienda, en el agro provinciano del sur, que vive sujeto a un sueldo mínimo y sin contrato, por lo que está condenado a la errancia y debe buscar el sitio en el cual tenga cabida al menos en parte (Brito, 2014, p. 37).

Así, Brito analiza cómo desde los órdenes de clase y de género operan diversas construcciones sígnicas en donde opresión y resistencia generan disputas territoriales en los diversos espacios y microespacios de las tramas de ambos textos. A partir de lo anterior, es posible establecer un pacto de asociación entre géneros y clases subordinadas, haciendo posible un análisis en donde los órdenes de clase y de género están estrechamente ligados y pueden leerse en su conjunción. Guerra afirma:

\footnotetext{
${ }^{2}$ La expresión "dialéctica sígnica" hace referencia a las permanentes disputas y tensiones de los signos y que terminan por configurar y determinar una obra. En el caso de Brunet, y para efectos de este artículo, pienso, primero, en las significaciones de lo femenino y lo masculino en Montaña adentro.

${ }^{3}$ En este sentido, es fundamental considerar el texto de Nelly Richard (2018).
} 
Carente de una cohesión social o cultural, de un ethos propio, la mujer, pese a su subordinación generalizada, no pertenece a un grupo social determinado sino que, por el contrario, está dispersa en todos los estratos configurados por la estructura económica. Situación que la inserta en una clase social determinada escindiéndola de las otras mujeres aunque, simultáneamente, comparte con ellas su condición femenina subordinada (Guerra, 1995, p. 74).

De esta manera, esa condición femenina subordinada de la mujer es también compartida por los sujetos explotados y dominados por una clase que encuentra en lo masculino su razón de ser. En la misma línea, se puede mencionar el trabajo de Bernardita Llanos, que ve replicado en la familia el mismo sistema patronal de explotación:

En el mundo de Brunet, la explotación del sistema patronal en el campo y la dinámica de dominio que establecen las relaciones laborales, se reactualizan en el espacio privado de la rancha. En este sitio el miedo y la sumisión al poder patronal de fuera, se ejerce adentro a través de la autoridad del hombre frente a su mujer e hijos (Llanos, 2000, p. 31).

Por su parte, Rubí Carreño aborda en su libro Leche amarga: violencia y erotismo en la narrativa chilena del siglo $X X$ lo femenino y masculino como relaciones de poder entre los personajes en donde:

(...) lo activo y lo pasivo, lo abierto y lo cerrado, lo español y lo indio, tendrían que ver no solo con categorías de género más o menos convencionales, sino con una construcción de géneros centrada en la sexualidad como práctica de poder y de violencia $^{4}$ (Carreño, 2007, p. 47).

Para Carreño, es fundamental pensar la hegemonía masculina fisurada con la irrupción de lo femenino y cómo la inestabilidad de las identidades va configurando las relaciones de poder entre los sujetos:

Las narrativas de Brunet y de Bombal pueden leerse como reflexiones realizadas desde el discurso literario sobre los modos en que la violencia se anuda al erotismo en la cultura chilena y en la que los géneros sexuales, por lo tanto, asumen alternadamente, las máscaras de víctimas y victimarios. Es decir, es un discurso que se articula a partir de la revelación de los secretos familiares/nacionales (Carreño, 2007, p. 43).

A las categorías aludidas por Carreño habría que agregar también el título de Montaña adentro, que refiere a la majestuosidad avasalladora de la elevación que se erige por sobre el resto del paisaje, pero también a ese espacio secreto del interior en donde transcurre el relato, un pueblo enclaustrado y castrado, en donde la montaña puede leerse, vinculándolo a la propuesta

\footnotetext{
${ }^{4}$ Carreño realiza una lectura desde los planteamientos de Sonia Montecino (1991) en Madres y huachos: alegoría del mestizaje chileno.
} 
de Amaro, como una mascarada fálica a la que hay que sortear para adentrarse en la particularidad precaria del pueblo y sus habitantes. De este modo, el título del cuento puede interpretarse como condensación sígnica de las nociones de lo femenino y lo masculino, en donde "(...) el criollismo sirve como una mascarada consciente para hablar sobre un problema que afecta a la sociedad en su conjunto" (Carreño, 2007, p. 195).

En este punto también resulta relevante la observación que realiza Martha E. Allen, en su estudio comparativo sobre la novela de Brunet y Bombal, cuando se refiere al rol activo del paisaje en Montaña adentro:

Es interesante observar el uso que hace Marta Brunet de la descripción del ambiente. Ya se ha mencionado la que contrasta el estado de degradación de los obreros con la serenidad y la alegría de la naturaleza circundante. En esta novela, sin embargo, las descripciones del paisaje aparecen frecuentemente como interrupciones a la narración: el súbito lirismo de una vista de la naturaleza interrumpe violentamente el curso de la relación de acontecimientos sombríos o trágicos. No están como un fondo para la acción, ni añaden nada al desarrollo de la historia, sino que detienen todo el movimiento de la novela (Allen, 1952, p. 67).

En efecto, en la novela la irrupción del paisaje rompe con la noción de género (textual y sexual) al otorgarle al elemento paisajístico un poder que convencionalmente no tiene. Es relevante señalar que, a diferencia de Llanos, que ve en el campo un elemento decorativo, Allen sugiere un protagonismo que permite reinscribir el territorio y desplazar el desborde hacia las nociones de lo femenino y lo masculino presentes en toda la obra.

En esa línea, Kemy Oyarzún, en su ensayo sobre la novela Amasijo (1962), precisa un tema que, a mi juicio, también puede encontrarse en Montaña adentro y que es piedra angular para este análisis: "Esa escena teatral abisma la novela, poniendo simultáneamente en tela de juicio la nitidez de los registros del género discursivo y del género sexual, precisamente a partir de las inversiones, yuxtaposiciones y reinscripciones de lo femenino y lo masculino" (Oyarzún, 2014, p. 882). Por otra parte, en el prólogo a la edición de Montaña adentro de 1997, Oyarzún, al hacer una revisión de cómo se ha leído y categorizado a Brunet desde la lógica femenina/masculina, comenta que:

Se iría configurando un mapa esquemático en el cual Brunet, la "chillaneja", y Bombal, la "viñamarina", podrían representar dos polos antitéticos de nuestra historia literario-cultural. La una designaría una escritura supuestamente "masculinizada", rural, provinciana, tosca, regionalista y "realista como una fotografía"; en tanto que la otra designaría una escritura "femenina" por excelencia, "vaporosa" y sutil, cosmopolita y surrealista (Oyarzún, 1997, p. 18).

Mi propuesta de lectura tiene que ver justamente con desordenar estas categorías fijas y tratar de identificar en Montaña adentro, su novela más masculina según los criterios anteriores, los signos de lo femenino y lo masculino cruzados, opuestos y superpuestos en el andamiaje literario de su construcción escritural. De esta manera, mi lectura de la obra busca romper desde adentro las oposiciones binarias del falogocentrismo en cuanto son construcciones históricas que, más que oponerse, fluyen. 


\section{El adentro y la montaña: correlato sígnico del simulacro}

Como en todo texto literario, el uso del lenguaje resulta fundamental para la construcción de la obra. Puede rastrearse el uso particular de cierto tipo de escritura y establecerla como huella del andamiaje utilizado para la construcción de la obra ya consolidada. En ese sentido, en Montaña adentro puede leerse cierto simulacro de legitimidad en la explícita diferenciación entre el lenguaje culto del narrador y el habla coloquial campesina utilizados para la construcción de la novela: "Un crujido seco y la máquina cortadora de trigo tumbóse a un lado" (Brunet, p. 115) contrapuesto al comentario "Güen dar con el asiento duro; tengo el cuerpo toíto molío" (Brunet, p. 116). Este último recurso de situar el habla campesina en la formalidad del texto literario fue cuestionado por la crítica literaria de la época, incluida Gabriela Mistral, que acusó a la chillaneja de un uso deformado del lenguaje.

Kemy Oyarzún le dedica un apartado a este tema y menciona que:

Desde una perspectiva atenta a la heterogeneidad cultural, la propia idea de un lenguaje purista podría ser vista como deformación, ligada a una aversión colonial por las mezclas y el mestizaje (...) Con la imposición colonial del castellano se normaría un tipo de lógica, un cierto repertorio de obsesiones y pasiones: la asociación de lo casto y puro con lo "castizo y viejo". Como nuestros países han sido muy vacilantes frente a las prácticas de democratización cultural y lingüística, la idea de pluralidad etnolingüística ha encontrado siempre profundas resistencias (Oyarzún: 1997, pp. 23-4).

Lorena Amaro lee en esta dinámica de oralidad brunetiana “(...) un alegato frente a la corriente devastadora de la norma, en otras palabras, frente a la construcción de una identidad nacional excluyente" (Amaro, 2014, p. 67). Su "depurado casticismo" y su "abajismo lingüístico" capaces de convivir en sus construcciones textuales serían signo de la rebeldía de Brunet. Así lo sostiene Kemy Oyarzún:

(...) contra una sociedad (chillaneja y nacional) que en más de una ocasión la escritora calificó de "pacata" por la estrechez de miras y rigidez estamental sociedad en extremo reacia a la diversidad linguiística, ética, ideológica, estética y sexual que sus textos convocaban y sus afirmaciones públicas reafirmaban (Oyarzún, 1997, p. 27).

De esta manera, esta resistencia a la normativa, el rebelarse contra la oficialidad de la lengua constituiría, de cierto modo, un cuestionamiento desde un habitar lingüístico minoritario.

El discurso centrado en las oposiciones jerárquicas, donde uno subordina al otro, procede de los discursos masculinos que se han instalado como sistema de significaciones universal y que Lucía Guerra describe como: "Adscribir significados a lo femenino es, en esencia, una modalidad de la territorialización, un acto de posesión a través del lenguaje realizado por un Sujeto masculino que intenta perpetuar la subyugación de un Otro" (Guerra, 1995, p. 14). Mi gesto es intentar desarticular ciertos engranajes desde el interior de ese paradigma. La pugna entre escritura y oralidad, que Brunet hace convivir en la textualidad de la novela, puede leerse 
como el ingreso de lo femenino al orden dominante de lo masculino, en donde este último está representado, por supuesto, por la lengua culta.

Sin embargo, hay que hacer una salvedad, pues la escritura de ese hablar coloquial de todas maneras respeta las normas gramaticales y de acentuación (escribe "güen” y no "wen”, y el "toíto" y "molío" están correctamente tildados según la regla del hiato). La anterior disonancia entre el decir coloquial, pero escribirlo apegado a cierta norma castiza, evidencia más bien un simulacro masculinizante que la escritora adopta al momento de construir su relato. Si bien Brunet, en su intencionalidad desmarcadora de la norma, incorpora el idiolecto campesino a su escritura, su gesto de todas formas se enmarca en el espacio que la norma oficial ofrece. Ahora bien, lejos de deslegitimar el gesto, me parece que esa disonancia revela la estrategia de Brunet en cuanto es capaz de entender que la incorporación a un orden dominante requiere de cierta asimilación minoritaria, una suerte de mimetización estratégica ${ }^{5}$ utilizada también por don Zacarías con sus peones: "En su ira, para mejor darse a entender, acudía a los modismos de ellos" (Brunet, p. 117). En ese sentido, puede afirmarse que la estrategia brunetiana se espejea en este personaje que, si bien tiene una posición más privilegiada (como Brunet), asume un habla que lo sitúa a la par de sus subordinados (como la escritura de Brunet).

Dentro de la misma "lógica dialógica" que se presenta, el administrador, cuya posición social está por sobre la de los peones, adopta el hablar coloquial marcando también una diferencia con la norma asumida y utilizada por el narrador, por lo que la dicotomía peón/administrador no necesariamente se condice con la que sí puede observarse entre personajes/narrador, habla/escritura e incluso entre femenino/masculino. En última instancia, los personajes son capaces de transitar de un lado a otro, difuminando las fronteras que se erigen como dicotomía genérica, superando así las tensiones adscritas y signadas exclusivamente a los cuerpos biológicos. En este punto se hace necesario enfatizar que el análisis que realizo de la obra de Brunet es, por supuesto, sexuado, pues tal y como lo plantea Guerra: "El género sexual es un conjunto de representaciones que en conjunción y tensión con otras representaciones crea significados, relaciones e identidades que fluctúan entre lo fijo y lo inestable" (Guerra, 1995, p. 15). Por lo mismo, puede leerse a Brunet desde lo que Nelly Richard concibe como escritura que descontrola las pautas de lo masculino/hegemónico: "Al rechazar toda coincidencia natural entre determinante biológica (ser mujer) e identidad literaria (escribir como mujer), podemos explorar las brechas y los descalces de representación que se producen entre la experiencia del género y sus puestas en escenas enunciativas" (Richard, 2008, p. 18). Lo femenino, que tensiona lo masculino dominante en Brunet, es precisamente, siguiendo a Richard, la metáfora activa de la marginalidad, la subversión y la disidencia, que pueden hallarse mucho más allá de la temática criollista en la que se ha enmarcado su literatura.

En este caso, cuando el administrador dice: "Se quebró... Se quebró... La quebrarían ustedes, rotos de miéchica... Apostaría que echaron la máquina por las piedras. ¿Es que no tenís ojos vos pa' mirar por onde echái los güeyes?" (Brunet, p. 117) devela otro de los simulacros dentro de la ficción misma, dentro de la historia, con la finalidad de darse a entender entre los sujetos subordinados. De esta forma, la máscara del criollismo -o del neocriollismo- “(...) pone en escena, no solo las relaciones intra e inter genéricas, sino también las existentes entre patrones e inquilinos" (Carreño, 2002, p. 49).

\footnotetext{
${ }^{5}$ Revisar el ensayo de Josefina Ludmer (1985).
} 
Volviendo a la idea anterior, de lo femenino/masculino en la escritura de Montaña adentro, y teniendo en cuenta el listado de premios nacionales con su abismal diferencia entre mujeres y hombres, la norma gramatical oficial, la escritura y el narrador pueden ser agrupados dentro de ese ámbito de lo masculino, el canon, lo validado social y culturalmente; mientras que lo femenino viene a estar representado por la figuración de una norma alternativa a la oficial (escribir imitando el habla, pero respetando las normas), el habla coloquial y los personajes de la ficción. Al igual que la escritura de Brunet, lo femenino en el relato pugna por lograr cierta pertenencia, siempre eso sí utilizando recursos estratégicos para lograr la asimilación.

Respecto a lo anterior, en el ensayo "Piedrazo al patriarcado", Carreño propone el criollismo de Brunet como:

(...) una máscara que, precisamente, le permite "decir" un problema que afecta a la sociedad en su conjunto. El idiolecto, la ambientación en la zona central de sus relatos, la semi amistosa jerarquía presente en las relaciones entre patrones e inquilinos, "la fatalidad" como motivo que justifica las inequidades, oculta la crítica que Brunet realiza a nuestra cultura (Carreño, 2014, p. 885).

Marta Brunet opta por supeditar el orden de lo femenino a la impostación masculina como andamiaje de la construcción literaria, pues sitúa ese coloquialismo dentro de un marco que es capaz de sostenerlo. Esto es, básicamente, que la norma alternativa no puede existir sin la norma oficial, el habla no puede existir sin la escritura, y los personajes no pueden existir sin el narrador; pero no ocurre lo mismo a la inversa. Por lo tanto, la presencia de lo femenino en Montaña adentro está siempre subordinado a la existencia de lo masculino. La obra viene a ser una suerte de correlato de lo que ocurre con la construcción y composición del canon literario nacional.

En cuanto a los personajes, el administrador don Zacarías es una fiel representación del poder masculino, pues los peones están subordinados a él:

Lo temían. Seguro de su omnipotencia, irascible, cualquier falta lo hacía despedir al trabajador. Y era eso lo que más temían, prefiriendo acatar todas sus arbitrariedades antes que perder el puesto. En los tiempos difíciles que corrían costaba encontrar trabajo y más aún conseguir puebla en algún fundo (Brunet, p. 117).

La relación anterior recuerda, por supuesto, a la que muchas veces se establece entre una mujer sumisa y un hombre dominante. Existe en la obra de Brunet una feminización del subalterno. Sin embargo, son también reconocibles los personajes que rompen con esta lógica y, de cierta manera, dislocan los roles asignados a lo femenino y a lo masculino. Llanos, al analizar el cuento "Piedra callada", afirma:

Esperanza simboliza a la mujer abusada por excelencia, cuya desconexión social contribuye a su aniquilamiento. Por el contrario, Eufrasia, su madre, representa una horma de negociación femenina en un mundo dominado por hombres. El ingenio, el engaño y finalmente, el asesinato, son sus armas contra el yerno que amenaza también con destruir a sus nietos (...) Con Eufrasia el estereotipo de la anciana débil queda desmantelado por el de un personaje femenino que opone la resistencia 
y el diseño de su propio repertorio de estrategias -aún las ilegales-. De este modo, la vieja se sale siempre con la suya como anunciara su yerno, eliminándolo para siempre (Llanos, 2000, pp. 33-4).

Doña Clara es también un reflejo de ese anterior andamiaje, pues construye una creencia alternativa a la religión oficial, ligada a esa masculinidad simbólica, tal y como los campesinos hablan su propia versión de la lengua oficial:

Años después llegó para una cosecha un fuerino que era "canuto" y el cual, en las noches, predicaba sus doctrinas a los peones, que ningún caso le hacían. Solo doña Clara le oía encantada narrar las parábolas, que eran para ella cuentos maravillosos. Fuera de estas historias y de aquello de no confesarse, la demás doctrina del “canuto” le era odiosa. ¡Bah! ¡Cómo que no! ¡La mamita Virgen era la mamita Virgen!... Tomando un poco y otro de allá, hizo una religión para su uso particular (Brunet, p. 130).

Ese desplazamiento de significados, que constituye la reinterpretación de las parábolas (suerte de ley o mandato directo de la voz de Dios) como cuentos maravillosos por parte de doña Clara es, además, un mecanismo del que se vale el sujeto subordinado para asimilarse al discurso oficial. Pensemos, por ejemplo, en la religiosidad latinoamericana que nace justamente del sincretismo cultural entre lo católico y lo indígena, una mascarada o simulacro que se erige como estrategia de sobrevivencia ante el sujeto dominante.

Ese Dios que todo lo ve y todo lo sabe se condice con la omnipotencia del narrador escogido por Brunet $\mathrm{y}$, por el contrario, el tratamiento alternativo que Juan Oses propone para bajarle la fiebre al recién nacido se condice con esa norma alternativa a la oficialidad. El tratamiento para el bebé está ligado más bien al saber popular no reconocido por la medicina alopática: “Aceite lo primero y na más que agüitas e anís pa' darle a pasto. Y pa' bajarle la fiebre la bañaban en agua bien calientita y l'arropaban después bien arropá pa' que suara harto. Y lueguito se refrescaba" (Brunet, 132). Por su parte, doña Clara ofrece sus rosarios a la mamita Virgen para sanar a la criatura (Brunet, p. 134) ${ }^{6}$.

La religiosidad propia de doña Clara no es solo sincretismo religioso, sino que su materialización es signo de la condensación femenino/masculino. De esta manera, surge un tercer espacio en donde lo hegemónico queda reducido a sustratos que conviven con las huellas de lo minoritario. Cata, por ejemplo, no se estanca en un rol históricamente asignado a la mujer, sino que transita por diversos espacios de transgresión a la norma, incluso con el que no debiese asumir una mujer:

Después de su aventura creyó doña Clara curada a Cata del mal de amores. Por mucho tiempo pareció que la maternidad había embotado en ella todo otro sentimiento. Mas, con la llegada de los fuerinos que acudían a los trabajos de las

\footnotetext{
${ }^{6}$ También para curar las heridas de un malogrado Juan Oses, Doña Clara y Cata recurren a la medicina natural y popular: "De toíto encontré, niña. Mira: matico pa' las herías..., natri pa' refrescarlo, yerba plata pa' darle agüitas..., toronjil pa' que olorose, y menta tamién" (Brunet, p. 154).
} 
cosechas, la vieja sintió renacer sus recelos viendo cómo Cata aceptaba las atenciones de Juan Oses (Brunet, p. 124).

De todas maneras, existe siempre una tensión entre estas dos fuerzas que están en permanente disputa, pues el saber popular de Juan Oses es cuestionado por los rumores de ser "hijo de rico" y pertenecer, de este modo, al ámbito de lo oficial-masculino. También hay que tener en cuenta que a Oses lo consideran y lo nombran como "afuerino", esto es, más allá del pertenecer territorial, un sujeto que está fuera del orden oficial. Sin embargo, en Juan Oses conviven actitudes y maneras (signos) asociadas históricamente a lo femenino y lo masculino, a ese lugar de subordinación:

Tenía el mozo un no sé qué de simpático y fino en las maneras y el mirar de sus ojazos negros atraía por la lealtad que emanaban. Grande y musculoso, había en él signos de otra clase afinada por la cultura; las manos y pies proporcionados y aún no deformes por la rudeza del trabajo, la amplitud de la frente, la suavidad del pelo que se quebraba en ondas. Entre los peones corría el decir que era hijo de rico (Brunet, p. 133) ${ }^{7}$.

Otro de los personajes en quien es posible observar cierto desplazamiento entre los ámbitos de lo femenino/masculino, o lo alternativo/oficial, es San Martín, el carabinero:

Este San Martín había sido en sus mocedades famoso cuatrero. A raíz de una larga condena cumplida en Talca y merced a la protección de cierto terrateniente había sentado plaza de carabinero (...) Ya que no era posible -le había costado muy largos y penosos años de encierro-, ya que no era posible ${ }^{8}$ matar y apalear gente por cuenta propia, los mataba y apaleaba en nombre de la justicia (Brunet, pp. 1389).

También se puede observar cómo la institución del matrimonio es otra de las estrategias utilizadas por los sujetos subordinados para asimilarse a la oficialidad, pues lo contrario, en el caso de Catalina, supone las habladurías y el eterno murmurar del pueblo:

Lo pior sería qu'este s'echara p'atrás y no quisiera na casarse. Con lo templá que me tiene, yo soy capaz d'irme y vivir con él así no más... Pero no, este es güeno..., este me quere de veras..., este se casará y naiden podrá entonces limpiarse su boca en mí. ¿Y si no quere? ¡Ay, Señorcito! (Brunet, p. 156).

Lo anterior, sin embargo, no ocurre con los personajes masculinos, en donde el engendrar hijos fuera del matrimonio no supone ningún tipo de condena social. En ese sentido, puede pensarse la paternidad -al contrario de la maternidad- desde la ausencia física, pero cuya

\footnotetext{
7 O cuando interactúa con el niño enfermo: "Juan Oses se arremangó rápidamente las mangas de la camisa y con suavidad insospechable en sus manos de peón, mantuvo al niño a flote” (Brunet, p. 135).

${ }^{8}$ La repetición aparece en la edición consultada.
}

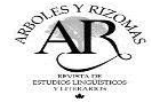


omnipresencia simbólica es determinante en la figuración de la masculinidad dominante. Juan Oses asume con el recién nacido un rol que no corresponde con los sujetos de su género.

¿Cuál es el costo de la rebelión en contra de la oficialidad? En el caso de Juan Oses, que es brutalmente apaleado por San Martín y luego apuñalado hasta la muerte por Pedro Pereria, el costo es evidente ${ }^{9}$. Esa resistencia está directamente relacionada con la inevitable fatalidad asumida desde siempre por Catalina:

Indiferente al calor y al cansancio, Cata se aislaba en sí misma. Tenía la muchacha ese fatalismo que hace acogerlo todo con igual calma. Dichas, pesares, enfermedades, muerte, son para ella poderes contra los cuales no vale rebelarse. ¿Para qué, si es el Destino? Ignorancia, miserias, malos instintos, el crimen mismo, son para ella poderes contra los cuales no vale luchar. ¿Para qué, si es la Fatalidad? (Brunet, p. 156).

De este modo, Brunet, al ir inscribiendo y diferenciando cada uno de los elementos dentro del ámbito de lo alternativo y lo oficial, viene a reproducir el sistema de subordinación y dominación, en donde lo masculino siempre predomina y, lo que escapa de manera evidente a esas lógicas, es, de cierta manera, castigado. Así, la escritura y composición de Montaña adentro es también un modo de asimilarse al modo de escribir oficial y, por supuesto, una estrategia para lograr acceder al canon históricamente masculino. Es relevante hacer explícito el desplazamiento de los significantes, correspondiendo peón, personajes y habla al lugar tradicionalmente designado para lo femenino, mientras que lo masculino tiene su lugar en sus directas oposiciones: administrador, narrador y escritura. De esta manera, se reproduce el signo femenino desde el relato patriarcal y adscrito al binarismo totalizante para, de cierta manera, desarticular esas posiciones y dar cuenta de que los elementos analizados fluyen y transitan por esos espacios signados. Los signos de lo femenino no tienen que ver con la expresión temática, sino que más bien apuntan al trabajo de la escritora dentro del formato de escritura, en donde puede observarse el descontrol de las pautas de lo masculino universal. Se piensa lo femenino en Montaña adentro al tensionar el modelo cultural dominante y queda la interrogante de si acaso es posible aplicar la misma lógica a las demás estéticas criollistas de la época, hecho que, en primera instancia, no sería posible, pues sería volver a inscribir la novela de Brunet en un espacio signado por la lógica patriarcal y, por otra parte, sería tratar de concebir esta lectura como totalizante, esfera de la que, por definición, se desinscribe. Las marcas de lo femenino y masculino en la escritura de Brunet se hallan cruzadas, opuestas y superpuestas tanto en la escritura misma, el uso del lenguaje; como en las actitudes, comportamientos y características de los personajes que no solo reproducen el rol asignado a un género específico, sino que más bien están en constante deambular entre un lado y otro, mostrando y ocultando, como una máscara que se utiliza para interactuar con el resto, articulando de este modo un complejo sistema de subjetividades y desplazamientos que constituye, finalmente, a los personajes de la novela en su permanente fluir entre los signos.

\footnotetext{
${ }^{9}$ Carreño (2014) menciona que "Cabe señalar que uno de los pocos hombres que se relaciona colaborativamente con las mujeres termina asesinado por otro hombre" (p. 889).
} 


\section{Bibliografía}

Allen, M. E. (1952). Dos estilos de novela: Marta Brunet y María Luisa Bombal. Revista Iberoamericana, 35, 63-91. https://doi.org/10.5195/REVIBEROAMER.1952.1482

Amaro, L. (2014). En un país de silencio: Narrativa de Marta Brunet. En N. Cisterna (Ed.), Marta Brunet: Obra narrativa. Novelas - Tomo I (pp. 15-87). Santiago: Ediciones Universidad Alberto Hurtado.

Bourdieu, P. (1990). El campo literario. Prerrequisitos críticos y principios de método. Criterios, 25-28, 20-42. La Habana, Cuba. Recuperado de http:/educacion.deacmusac.es/practicaslegitimadoras/files/2010/05/bourdieucampo.pdf

Brunet, M. (2014). Montaña adentro. En N. Cisterna (Ed.), Marta Brunet: Obra narrativa. Novelas - Tomo I (pp. 115-170) Santiago: Ediciones Universidad Alberto Hurtado.

Brito, E. (2014). Ficciones del muro: Brunet, Donoso, Eltit. Santiago: Editorial Cuarto Propio.

Carreño, R. (2002). Una escena crítica: Estereotipos e ideologías de género en la recepción crítica de Marta Brunet y María Luisa Bombal. Anales de Literatura Chilena, 3, 43-51.

Carreño, R. (2007). Leche amarga: violencia y erotismo en la narrativa chilena del siglo XX. Santiago: Editorial Cuarto Propio.

Carreño, R. (2014). Piedrazo al patriarcado. En N. Cisterna (Ed.), Marta Brunet: Obra narrativa. Novelas - Tomo I (pp. 881-903) Santiago: Ediciones Universidad Alberto Hurtado.

Guerra, L. (1995) La mujer fragmentada: Historias de un signo. Santiago: Editorial Cuarto Propio.

Llanos, B. (2000) Transgresión y violencia sexual en Marta Brunet. Mapocho, 48, 29-37.

Ludmer, J. (1985) Las tretas del débil, en González, P. \& Ortega, E. (Eds.), La sartén por el mango, (pp. 47-54). Rio Piedras, Puerto Rico: Ediciones El Huracán.

Oyarzún, K. (1997). Prólogo. Montaña adentro. Marta Brunet. Santiago: Universitaria.

Oyarzún, K. (2014). Teatralidad del género. Inquietud del sexo. En torno a Amasijo de Marta Brunet. En N. Cisterna (Ed.), Marta Brunet: Obra narrativa. Novelas - Tomo I (pp. 879898). Santiago: Ediciones Universidad Alberto Hurtado.

Richard, N. (2008). ¿Tiene sexo la escritura? Feminismo, género y diferencia(s). Santiago: Palinodia.

Zamorano, C. (2014). Eugenia Brito, Ficciones del muro: Brunet, Donoso, Eltit. Catedral Tomada. Revista de crítica literaria latinoamericana, 2(3), 175-181. https://doi.org/10.5195/CT/2014.79 